\title{
ЭЛЕКТРОННЫЕ БИБЛИОТЕКИ КАК СРЕДСТВО ФОРМИРОВАНИЯ ЧИТАТЕЛЬСКИХ КОМПЕТЕНЦИЙ УЧАЩИХСЯ
}

\section{ELECTRONIC LIBRARIES AS A MEANS OF FORMING STUDENTS' READING COMPETENCIES}

\section{Kulikova}

Summary: Adolescents do not effectively use modern electronic resources in daily and school life, so it is necessary to improve intentional reading skills as an element of school students' reading competency. Electronic libraries are aimed at achieving learning outcomes to form and develop school students'reading competencies. With this in mind, specifictexts and media should produce an emotional response in school students reading the material of social importance. It is important to consider conditions to form and develop reading competencies, as well as follow the structure of a lesson in order to achieve personal and metasubject outcomes. The article describes examples of developing intentional reading skills when school students use the resources of electronic libraries: Weblandia, Runivers, Russian state children's library, International children's digital library, and Boris Yeltsin presidential library. There is revealed the potential of the resources, which contributes to forming and developing school students' reading competencies; it includes opportunities to be involved in situations of social importance and emotional response. In turn school teachers gain opportunities to strengthen the practice of developing intentional reading skills in school students.

Keywords: electronic library, reading competency, social situations, intentional reading.

\author{
Куликова Марина Юрьевна \\ Учитель, МБОУ «Гимназия №48 г. Челябинска» \\ chel.gimn48@yandex.ru
}

Аннотация: Необходимость развития навыков осмысленного чтения, являющихся элементом читательской компетенции учащихся, продиктована тем, что подростки ограниченно используют современные электронные ресурсы в повседневной жизни и учебной деятельности. Электронные библиотеки призваны помочь в достижении образовательных результатов, связанных с формированием и развитием читательских компетенций учащихся. С этой целью размещенные на веб-сайтах специализированные тексты и медиафайлы должны вызывать эмоциональный отклик у учащихся в процессе осмысленного чтения социально значимого материала. Учет условий формирования и развития читательских компетенций, а также соблюдение структуры занятия способствуют достижению личностных и метапредметных результатов. В статье описаны примеры развития навыков осмысленного чтения в процессе использования ресурсов электронных библиотек: ВебЛандии, Руниверс, Российской государственной детской библиотеки, Международной электронной детской библиотеки и Президентской библиотеки имени Б.Н. Ельцина. Выявлен потенциал данных ресурсов в формировании и развитии читательских компетенций учащихся, который заключается в возможности быть вовлеченными в социально значимые ситуации, вызывающие их эмоциональный отклик. В свою очередь учителю открываются возможности усилить практику развития у учащихся навыков осмысленного чтения.

Ключевые слова: электронная библиотека, читательские компетенции, социально значимые ситуации, осмысленное чтение.
$\mathrm{X}$ XI век - век информационных технологий, которые проникают в различные сферы современного общества, в том числе в образование. Учителя уже не представляют свою жизнь без электронных классных журналов и дневников (например, Сетевого города), онлайн-платформ для проведения занятий и видеоконференций (например, ZOOM), родительских и детских чатов в различных мессенджерах (например, Viber). Но использование многообразных электронных ресурсов ограничивает учащихся в осмысленном чтении, позволяющем им постигать базовые ценности современного общества, развивать социально значимые отношения, приобретать соответствующий опыт поведения и применять его на практике (Чурляева, 2010). В связи с этим отмечается противоречие. С одной стороны, подростки каждую минуту встречаются с дисплейными текстами, включающими в себя видео, фото, подписи, невербальные средства общения (смайлы, стикеры и т.п.). С другой стороны, они теряют навык вычленения главной информации при работе с текстами, то есть современные школьники обладают навыками осмысленного чтения на минимальном уровне.

Навыки осмысленного чтения - неотъемлемый элемент читательской компетенции учащихся, которая определена новыми Федеральными государственными образовательными стандартами второго поколения (ФГОС). Читательская компетенция - это «совокупность знаний, умений и навыков, позволяющих человеку отбирать, понимать, организовывать информацию, представленную в знаково-буквенной форме, и успешно её использовать в личных и общественных целях» (Кольчикова, 2013, с. 177). Возникает вопрос, связанный с недостаточным уровнем у учащихся навыков осмысленного чтения: как формировать и развивать читательские компетенции учащихся? Среди возможных путей решения данной проблемы, а соответственно и достижения образовательных результатов - использование ресурсов электронных библиотек. 
Электронная библиотека представляет собой иерархизированную информационную систему с упорядоченным собранием разнородных электронных документов, которыми можно пользоваться благодаря глобальным интернет-сетям передачи информации (Саханский, Касаева, 2017). Электронная библиотека может являться вебсайтом, на котором постепенно размещаются и накапливаются различные тексты (от литературных до научных) и медиафайлы, к каждому из которых читатель имеет свободный или авторизированный доступ. Электронные библиотеки могут быть универсальными, стремящимися к предоставлению текстов и медиафайлов, объединённых широкой тематикой (к примерам можно отнести Библиотеку Максима Мошкова и Либрусек), и специализированными, охватывающими смежные области знаний (примерами являются Фундаментальная электронная библиотека и проект Сетевая Словесность). При этом социально значимые электронные ресурсы играют существенную роль в достижении образовательных результатов (Ершова, Хохлов, 2001).

Тексты и медиафайлы должны вызывать эмоциональный отклик у учащихся, в связи с чем расширяется спектр эмоций, которые они испытывают при знакомстве и анализе произведений искусства слова, имеющих социальную значимость. Развитие умения сопереживать, или эмпатии, происходит в процессе творческого изучения данных произведений. Так содержание ресурсов электронных библиотек влияет на эмоциональное состояние учащихся в процессе осмысленного чтения социально значимого материала. Подобный материал может отражать поиск жизненного пути и ситуации трудного нравственного выбора. Этому особенно способствует современная литература, которая описывает реалии, понятные для обсуждения подростками XXI века для разрешения внутренних и внешних конфликтов. Именно данная литература служит отправной точкой для индивидуального понимания ее своеобразия (Сафронова, 2017).

При формировании и развитии читательских компетенций учащихся на основе текстов и медиафайлов, размещенных в электронных библиотеках, необходимо учитывать несколько условий. Во-первых, произведения искусства слова должны соответствовать возрастным особенностям учащихся для того, чтобы они могли эффективно проанализировать имеющийся социально значимый материал. Вторым условием выступает материал, содержание которого максимально приближено к реальным ситуациям подростков, которые позволяют выстраивать новые модели поведения. В-третьих, важна ценность произведения искусства слова, которое должно отличаться глубиной и многоплановостью, поскольку сила их воздействия на учащихся призвана достичь запланированных образовательных результатов. Тексты и медиафайлы должны отличаться новизной, которая выступает четвертым условием; отсутствие определенных ассоциаций, связанных с произведениями искусства слова, - хорошая основа для обсуждения социально значимых ситуаций.

Выделенные условия необходимо учитывать в индивидуальной, парной и групповой формах работы, позволяющих оптимально формировать и развивать читательские компетенции учащихся на систематической основе (Руснакова, Ковтун, 2016). При этом структура занятия отличается одноплановостью, включая организационный момент, работу с текстом и/или медиафайлом, обсуждение социально значимой ситуации в ходе осмысленного чтения, использование приемов для достижения образовательных результатов, инсайт как новый взгляд на социально значимую ситуацию, рефлексию, вопросы для самостоятельных размышлений. Благодаря подобной структуре занятия ресурсы электронных библиотек целенаправленно воздействуют на эмоциональное состояние учащихся.

Личностные и метапредметные результаты достижимы в ходе формирования и развития читательских компетенций учащихся, поскольку при этом развиваются «мягкие» навыки. К ним отнесены организация командной работы, ведение переговоров и договоренности со сверстниками, креативность и способность адаптироваться к изменениям. Также важно при взаимодействии с обществом использовать навыки осмысленного чтения, связанные с поиском информации и пониманием текста и/или медиафайла, преобразованием и интерпретацией информации, ее оценкой (Ходякова, Супрунова, 2016). Критическое восприятие информации - важный навык в современном обществе (Баканова, Мухамадеева, 2015).

Далее рассмотрены наиболее популярные электронные библиотеки (ВебЛандия, Руниверс, Российская государственная детская библиотека, Международная электронная детская библиотека и Президентская библиотека имени Б. Н. Ельцина), и описано, каким образом они помогают практикующему учителю формировать и развивать читательские компетенции учащихся.

- ВебЛандия представляет собой каталог лучших безопасных сайтов для детей и их родителей. Сайты проверяются и отбираются специалистами-психологами. С помощью данного ресурса целесообразно организовать урок или фрагмент урока на основе межпредметных связей, например, геометрии и искусства. Возможными формулировками заданий могут стать следующие: «Проанализируйте статью, материалы сайта, подумайте, какие геометрические фигуры легли в основу различных архитектурных сооружений». На основе данных материалов учащиеся могут создать презентацию, интеллект-карту, чертёж и т.п. Можно использовать материалы сайта как основу проектной деятельности учащихся, которые 
в группах работают над решением социально значимой проблемы.

- Руниверс - один из ведущих проектов по истории России в интернете. Это уникальная база данных, содержащая факсимильные постраничные изображения более 3000 томов, изданных в России в XIX - начале XX века, уникальную коллекцию из 3900 карт и свыше 20000 исторических иллюстраций и фотографий. Интересно будет предложить учащимся создавать небольшие сообщения под рубрикой «Исторический календарь» или «Календарь событий»; гуманитарная направленность данных сообщений будет более выигрышной. Таким образом 2-3 минуты начала урока будут не просто организационным моментом, а тем этапом, который и настраивает на урок, и мотивирует учащихся, и развивает их творческие способности, и помогает бороться с опаздывающими. Можно объявить конкурс на самое яркое и интересно представленное сообщение в данной рубрике, поставив не одну, а три «пятёрки» победителю самого лучшего сообщения, например, по итогам четверти или полугодия.

- Российская государственная детская библиотека - это крупнейшая в мире библиотека для детей. Она основана 30 декабря 1969 года как культурно-просветительский центр для детей и их родителей. Разумно использовать данный электронный ресурс при работе с учащимися, которые часто пропускают уроки в связи с болезнью, соревнованиями и по другим причинам. Так, например, по географии будет интересным изучить материалы выставки самостоятельно, создав сообщение, презентацию или составив вопросы, викторину и т.п. на отдельную оценку. Так можно работать и с неуспевающими учениками, чтобы они могли улучшить свою отметку.

- Международная электронная детская библиотека - это библиотека для детей всего мира, которая включает лучшие произведения современной и классической детской литературы. На сегодняшний день коллекция Международной библиотеки включает 4468 книг на 55 языках. Данный ресурс представляет прекрасную возможность заглянуть и полистать книги на персидском, испанском, турецком, японском, датском и многих других языках. Основной задачей электронной библиотеки является создание книжного фонда из более чем
10000 книг на 100 языках, которые могут читать бесплатно дети, учителя, библиотекари, родители и ученые в любой точке мира, используя сеть интернет. В отличие от предыдущего ресурса, к которому уместнее привлекать отстающих учащихся, рекомендуется обратиться к международной библиотеке одарённым учащимся: олимпиадникам, конкурсантам. Можно посоветовать сделать план, выписать названия глав, создать рисунок к понравившемуся эпизоду не просто книги на иностранном языке, а к изданию, признанному на международном уровне.

- Президентская библиотека имени Б.Н. Ельцина открыта 27 мая 2009 года и функционирует как общегосударственное электронное хранилище цифровых копий важнейших документов по истории, теории и практике российской государственности, русскому языку, а также как мультимедийный многофункциональный (культурнопросветительский, научно-образовательный и информационно-аналитический) центр, имеющий статус национальной библиотеки России. Этой библиотекой можно воспользоваться тогда, когда нет возможности очно провести урок (во время морозов, карантина), когда дистанционные технологии являются неотъемлемой частью образовательного процесса. Например, в помощь учителю представлен учебный фильм на тему «Русская правда», ссылку на который можно легко выслать через Сетевой город и другими способами. Здесь же можно найти онлайн-тестирование на представленную тему, чтобы облегчить работу учителю в составлении контрольных измерительных материалов.

Таким образом, анализ ресурсов основных существующих электронных библиотек показал их потенциал в формировании и развитии читательских компетенций учащихся. Потенциал заключается в возможности учащихся быть вовлеченными в социально значимые ситуации, которые вызывают их эмоциональный отклик. Личностные и метапредметные результаты достижимы в процессе изучения и анализа социально значимых текстов и медиафайлов, размещённых в электронных библиотеках. Ресурсы ВебЛандии, Руниверса, Российской государственной детской библиотеки, Международной электронной детской библиотека и Президентской библиотеки имени Б.Н. Ельцина открывают учителю возможности усилить практику осмысленного чтения.

\section{ЛИТЕРАТУРА}

1. Баканова Е.Н., Мухамадеева 3.В. Становление личности современного школьника через формирование читательской компетенции // Педагогическое мастерство и педагогические технологии. - 2015. - № 1 (7). - С. 114-115. 
2. Ершова Т.В., Хохлов Ю.Е. Опыт и перспективы интеграции российских социально значимых электронных информационных ресурсов на основе концепции электронных библиотек // Электронные библиотеки. - 2001. - № 4 (1). - Режим доступа: https://elbib.ru/article/view/107

3. Кольчикова Н.Л. Формирование читательских компетенций школьника в процессе литературного образования // Вестник ТГПУ. - 2013. - № 4 (132). С. 177-180.

4. Руснакова Е.В., Ковтун И.Н. Читательская компетенция как составляющая общекультурной компетенции обучающихся общеобразовательной школы // Современные технологии в науке и образовании: проблемы, достижения, перспективы: сборник науч. трудов по мат-лам I междунар. науч.-практ. конф., Стерлитамак 15 декабря 2016 г. - Изд-во: 000 «Вектор науки».

5. Сафронова Е.С. Читательская компетенция учителя русского языка и литературы как основа формирования читательской культуры обучающихся // Модернизация системы профессионального образования на основе регулируемого эволюционирования: мат-лы XVI Междунар. науч.-практ. конф., Москва - Челябинск, 14 ноября 2017 г. - Изд-во: Челябинский институт переподготовки и повышения квалификации работников образования.

6. Саханский Ю.В., Касаева Д.Р. Современные электронные библиотеки: задачи их деятельности и современные пути их развития // Инновационная наука. - 2017. - № 12. - С. 58-62.

7. Х Ходякова Л.А., Супрунова, А.В. Читательская компетенция как составляющая общекультурной компетентности (диагностика метапредметных умений) // Наука и школа. - 2015. - № 6. - С. 87-94.

8. Чурляева Т.Н. Формирование читательской компетенции в условиях современного общества // Философия образования. - 2010. - № 3 (32). - С. 172-178.

○ Куликова Марина Юрьевна (chel.gimn48@yandex.ru).

Журнал «Современная наука: актуальные проблемы теории и практики»

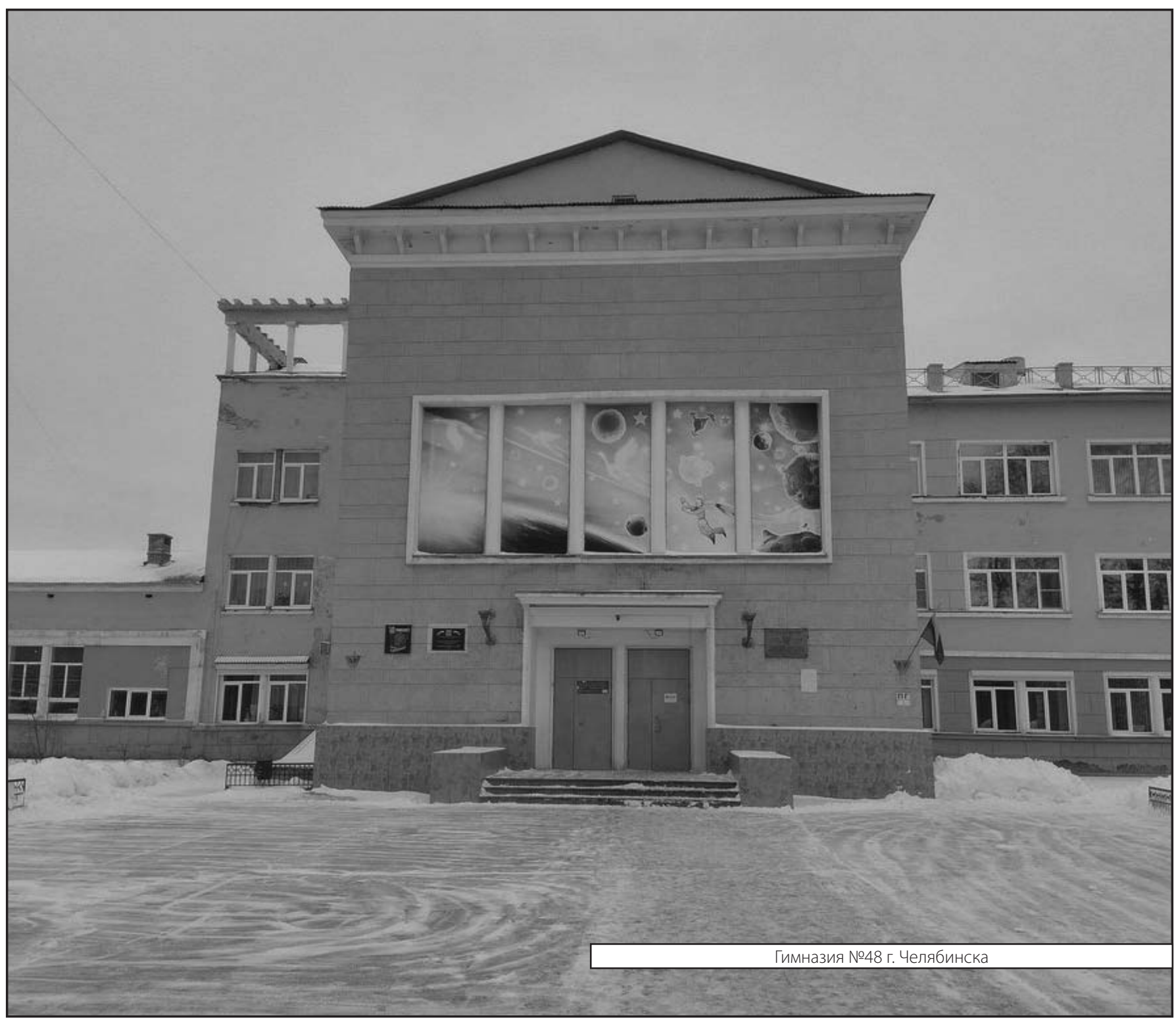

